with no suspicion of fluctuation or egg-shell crackling about it, the skin and muscles were not implicated, but the superficial veins were a little prominent and there was an enlarged gland in the right axilla. The arm was wasted and the muscles were weaker than those of the opposite side; the movements of the elbow-joint were unimpaired. Pain was only complained of when using the arm or on applying firm pressure. No other bone abnormality could be made out. There was no history of injury or of fracture, and the question of syphilis was carefully gone into, but no evidence

FIG. 2.

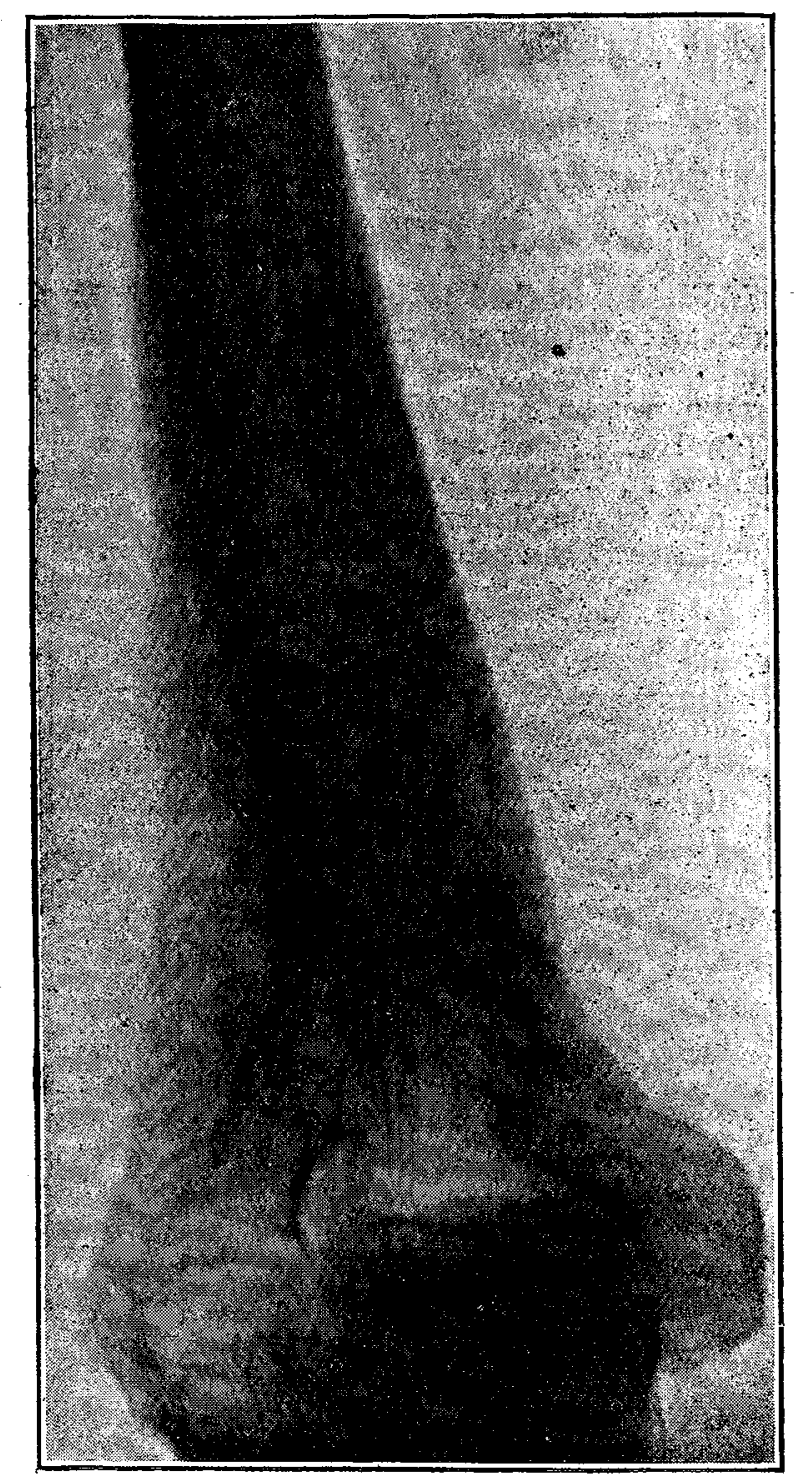

Reproduction of skiagram taken on Feb. 1st, 1909, showing maintenance of improvement.

of it could be obtained. The skiagrams showed marked shanges in the structure and outline of the bone, and suggested to most of those who saw them the presence of a new growth.

*. To exclude the possibility of a syphilitic origin mercury and potassium iodide in increasing doses were given for ten days, but as at the end of that time the swelling had increased both in measurement and as seen by skiagram, that treatment was abandoned, and the patient was advised to submit to an exploratory operation, to be followed if necessary by amputation ; this, however, she refused to agree to, and, as an alternative, treatment by Coley's fluid was suggested and adopted.

We began with half-minim doses and increased them by quarter, half, and one minim until a maximum of nine minims was reached; the first injections were given into the arm outside the limits of the growth, but the later ones were injected into it, and 23 injections in all were given. They were followed by pain and swelling at seat of injection, with general malaise and headache, nausea and vomiting, and pains in the limbs and joints followed by the appearance of subcutaneous hæmorrhages resembling bruises, but with only slight rise of temperature and increase of pulse-rate. 'These after-effects were so unpleasant that we had some difficulty in persuading her to continue the treatment; she, however, submitted to it until August 13th, when the swelling had almost disappeared and the structure and outline of the bone had resumed its normal appearance.

A skiagram taken on Feb. 1st, 1909, shows that the improvement has been maintained.

Devonshire-street, $\mathbf{W}$.

\section{A NOTE ON NORMAL MENSTRUATION WITH ABSENCE OF THE BODY OF THE UTERUS.}

BY ALEXANDER BROWN, M.B. LOND., M.R.C.S. ENG.

THE patient, who had been married for nearly three years, consulted me on account of sterility. She was most desirous of having a child. Bred in the country and of fine physique she had been perfectly regular in her periods from the age of 13 years. She was now 28 years old, about the same age as her husband, who was tall but not so strong-looking as herself. The periods lasted for four or five days and an experienced nurse testified to the normal loss. This nurse, who had known the patient from infancy, informed me that although she knew her to be an affectionate wife and very fond of children she was sexually cold and during childhood had pursued the sports of boys and had formed no girl acquaintanceships.

I examined the patient in bed, and bimanually could find no uterus and I failed to introduce a sound. On withdrawing my finger there was a little blood; the vaginal cervix appeared to be of normal size and shape but was congested, and the blood evidently came from the external os. I advised a full examination under an anæsthetic. Accord. ingly a few days later I placed the patient under ether, and my friend Dr. A. Alexander conducted the examination, the result of which I afterwards confirmed. He found complete absence of the body of the uterus. On bimanual examination the state of the pelvic contents was striking; the examining finger and the outside hand clearly approximated with the vaginal cervix alone between them. There was absolutely nothing to be felt within the pelvis to represent the body of the uterus.

I am aware that a post-mortem examination could alone disclose the exact representation of the parts and that developmentally a uterus might then be demonstrated, but the case appears to be of considerable interest in that so gross a deficiency existed with normal monthly periods. No doubt the vaginal cervix supplied the monthly loss.

Bartholomew-road, N.W.

A Futile Inquest.-An inquest reported in the Western Gazette of May 7th affords another proof that the coroner's law is in urgent need of reform. The jury were directed to inquire into the death of a woman, aged 28 years, who had died suddenly with symptoms of severe abdominal pain before the medical man who was summoned could reach the house at Thornford where she resided as housekeeper. No poisonous substance was found in the room. The witnesses who spoke as to the nature of the symptoms were unskilled, and no medical evidence was called nor was any necropsy made. The jury told the coroner that "Deceased appeared to have died from natural causes," and the coroner replied that "he had entered the statement that deceased was suddenly taken ill and suffered from severe pains, probably due to indigestion, which caused acute gastritis, and that she died in a natural way and not in an unlawful way." This elicited a protest from the foreman to the effect that "the jury said 'appeared' to have died," to which the coroner replied that "it was the same thing." Accepting the report as correct, the jury appears to us to have had a much sounder view of the nature of the evidence than the coroner. Howerer the woman died, the coroner has taken a heavy responsibility in neglecting to prove his supposition as to the cause of her death in the only possible way-i.e., by ordering a post-mortem examination to be made. In the absence of any medical evidence the jury in effect very properly refused to bring in a verdict, and we trust it will afford a salutary lesson to the coroner in question on the futility of guess-work inquests. 